\title{
Correlation of Climate Change Indicators with Health and Environmental Data in the Philippines
}

\author{
Jinky Leilanie Lu, MOH, PhD \\ National Institutes of Health, University of the Philippines Manila
}

\begin{abstract}
Introduction. The Lancet Countdown used Global Burden of Disease (GBD) data to track mortality from diseases influenced by climate change. The Philippines is one of the most vulnerable nations to climate change.

Objective. This study aimed to provide summative data on climate change and health-environmental factors based on several large databases. It looked into the correlation of climate change to selected health variables and correlated environmental factors to health chosen variables in the Philippines.

Methods. The database was assembled through a compilation of different secondary data. Climate change variables were acquired from the Global Burden of Disease (GBD 2017) Study on Health-related Sustainable Development Goals Indicators from 1990 to 2030 . The data for the Philippines were obtained. These indicators include air pollution mortality, disaster mortality, household air pollution, malaria incidence, mean $\mathrm{PM}_{2.5}$, non-communicable disease mortality, neglected tropical diseases mortality, unimproved sanitation, and unsafe water. The resulting database was analyzed using exploratory data analysis techniques with descriptive statistics and line graphs to analyze trends over the years. Then Pearson correlation analysis was done to explore the linear relationship between health indicators, climate indicators, and environmental indicators.
\end{abstract}

Results. The study results showed that the trend in the Philippines for air pollution mortality, household air pollution, malaria incidence, and neglected tropical diseases mortality is in a downward direction. However, non-communicable disease mortality was constantly increasing from 41.99 in 1990 to 55.00 in 2016 . Meanwhile, the mean temperature is significantly negatively correlated to household air pollution, malaria incidence, and neglected tropical diseases and significantly correlated with non-communicable diseases. Also, NOAA adjusted sea level is significantly positively correlated with air pollution mortality, malaria incidence, disaster mortality, and non-communicable diseases. It is negatively correlated with malaria incidence and neglected tropical diseases prevalence. Global mean $\mathrm{CO}_{2}$ is significantly negatively correlated with household air pollution, malaria incidence, and neglected tropical diseases prevalence.

On the other hand, it was significantly and positively correlated with air pollution mortality and non-communicable diseases mortality. Household air pollution health risk was significantly positively correlated to mean $\mathrm{PM}_{2.5}$ levels in the Philippines. Unimproved sanitation was positively correlated with household air pollution, malaria incidence, and neglected tropical disease prevalence.

Conclusion. As recordings of heat index increased, there was a correlation with NCD, Malaria, Disaster, and NTD infection mortality. With the evidence of the correlation of increasing temperature and pollution to health, the urgency to focus on addressing these problems was present in this study. Further research may help in policymaking to target drivers of pollution which affect extreme climate changes.

Key Words: climate change, Philippines, air pollution, unsanitary water, sea level, $\mathrm{CO}_{2}$ and $\mathrm{PM}_{2.5}$

Corresponding author: Jinky Leilanie Lu, $\mathrm{MOH}, \mathrm{PhD}$

National Institutes of Health

University of the Philippines Manila

623 Pedro Gil Street, Ermita, Manila 1000, Philippines

Email: jdlu@up.edu.ph 


\section{INTRODUCTION}

There has been a continuous increase in environmental temperature in the past several years. With each decade being warmer than the last, glaciers have been melting, rising sea levels and the weather have been more extreme. ${ }^{1}$ With the Global Burden of Disease (GBD) Study in 2017, over 3,600 researchers conducted a comprehensive assessment of 359 diseases and injuries in 195 countries and territories from 1990 to $2017 .^{2}$ This program assessed disability and mortality from major diseases well as their risk factors. The Lancet Countdown used GBD data to track mortality from diseases that are influenced by climate change. ${ }^{3}$ This report was the basis for selecting which variables in the GBD Study will be included in this study. These climate changes, mainly driven by the dramatic increase of greenhouse gas emissions from anthropogenic activities, can affect human health in several ways. These include an altered distribution of vector-borne diseases such as malaria and neglected tropical diseases such as dengue. The cardiopulmonary system and the gastrointestinal tract are also directly and indirectly affected variables correlated to climate change, such as carbon dioxide $\left(\mathrm{CO}_{2)}\right.$ levels and particulate matter $\left(\mathrm{PM}_{2.5}\right)$ levels. It was also observed and projected that climate change affected and will continue to affect increases in diseases-mainly air pollution-related diseases and heat-related illnesses.

This study provided summative data on climate change factors and health-environmental factors based on several large databases. This study also aimed to establish a relationship between global climate indicators and environmental factors in the Philippines against selected health factors. The null hypothesis assumed for the correlation analyses is no linear relationship between climate change and health factors.

\section{METHODS}

The goal of this analysis was to investigate how climate change affects selected health variables in the Philippines. To do this, first, a database was assembled through a compilation of different secondary data. This database comprised data obtained from the GBD Study 2017, US-NASA Goddard Institute of Space Institute Surface Temperature Analysis (NASA-GISTEMP), US Environmental Protection Agency (US-EPA), National Oceanic and Atmospheric Administration - Earth System Research Laboratories (NOAAESRL), The Intergovernmental Panel on Climate Change (IPCC), National Space Science and Technology Center the University of Alabama in Huntsville (NSSTC-UAH), US data.gov, Commonwealth Scientific and Industrial Research Organisation (CSIRO), and University Corporation for Atmospheric Research (UCAR). ${ }^{4-13}$

In this study, climate change is defined as the alteration of the temperature, and typical weather pattern becomes less predictable and can impact human life. The environmental factor is defined as those physical, chemical, or biological variables or a group linked to climate change due to human activity. Health factors are the health impacts of climate change such as air-borne, water-borne, and land-borne diseases.

\section{Climate Change Variables}

The climate change variables are some critical indicators for climate change that are monitored across the globe. These variables show trends over time about how climate and environmental conditions are changing. In this study, the following variables are explored:

Mean Temperature Anomaly: This data came from the NASA-GISTEMP analysis. The values are the annual average of combined Land-Surface Air and Sea-Surface Water temperature anomalies, that is, the deviations from the corresponding 1951-1980 means. ${ }^{5}$

CSIRO adjusted Sea Level: This is the global average absolute sea-level change from 1880 to 2013 measured by the CSIRO. ${ }^{12}$

NOAA adjusted Sea Level: This is the global average absolute sea-level change from 1880-2014 measured by the NOAA. ${ }^{7}$

Note: Both the CSIRO and NOAA data refer to the height of the ocean surface, regardless of whether nearby land is rising or falling. Satellite data are based solely on measured sea level, while the long-term tide gauge data include a small correction factor (adjustment) because the size and shape of the oceans are changing slowly over time.

Mean $\mathrm{CO}_{2}$ Global: This dataset is a global average of measurements over marine surface sites. The values are the annual mean $\mathrm{CO}_{2}$ mole fraction determined from daily averages. The data is reported as dry air mole fraction, defined as the number of $\mathrm{CO}_{2}$ molecules divided by the number of all molecules in the air, including $\mathrm{CO}_{2}$ itself, after removing water vapor. The mole fraction is expressed as parts per million (ppm). ${ }^{8}$

Climate change variables were acquired from the GBD 2017 Health-related Sustainable Development Goal (SDG) Indicators, 1990 to $2030 .{ }^{4}$ Their goal was to assign a Healthrelated SDG Index score on each country using 41 individual indicators. While in the GBD, the indicators were "scaled values" from 0-100, which showed how far a country was from achieving its goal in that indicator; the values used in the study were the "unscaled values," which were the actual estimates of the indicators.

\section{Health Variables}

Data for the Philippines was obtained for this study. The following indicators were included as they were perceived to be health problems associated with global climate change, as suggested by the Lancet Countdown on health and climate change 2018. ${ }^{14}$ The variables included here were:

Air Pollution Mortality in the Philippines: Age-standardized death rate attributable to household air pollution or ambient air pollution per 100,000 population. 
Disaster Mortality in the Philippines: Death rate due to exposure to forces of nature per 100,000 population.

Household Air Pollution Health Risk in the Philippines: Health Risk-weighted prevalence of household air pollution, measured by the summary exposure value (SEV) for household air pollution, in percent (\%). According to the GBD Study glossary, SEV is "A measure of a population's exposure to a risk factor that takes into account the extent of exposure by risk level and the severity of that risk's contribution to disease burden." Hence, it is a health variable. $^{4}$

Malaria Incidence in the Philippines: Age-standardized rate of malaria cases per 1000 population

Non-communicable Diseases Mortality (NCD) in the Philippines: Age-standardized death rate due to cardiovascular disease, cancer, diabetes, and chronic respiratory disease in 30 to 70 , per 10,000 population.

Tropical Diseases Mortality in the Philippines: Agestandardized prevalence of the sum of 15 neglected tropical diseases (NTDs), in percent (\%).

The data set was obtained from the GBD Study 2017, and the sources indicated in the definition of terms. There was no transformation of data in this study. The data was collated into one database to correlate climate change, health, and environmental variables.

\section{Environmental Variables}

Environmental variables were also taken from the GBD 2017 Health-related SDGs, 1990 to $2030 .{ }^{4}$ These variables were indicators in the GBD Study 2017 that measured environmental factors affecting the population's health. In particular, for this study, only data from the Philippines was obtained. The variables included were:

Mean $\mathbf{P M}_{2.5}$ in the Philippines: Population-weighted mean levels of fine particulate matter smaller than 2.5 microns in diameter.

Unimproved Sanitation in the Philippines: Riskweighted prevalence of populations using unsafe or unimproved sanitation as measured by the SEV for unsafe sanitation, in percent (\%).

Unsafe Water in the Philippines: Risk-weighted prevalence of populations using unsafe or unimproved water sources, as measured by the SEV for unsafe water, in percent (\%).

The database created was for 1990 to 2017 since it was the interval for which most of the variables included were complete. Most of the variables were empty for earlier years, while most data were projections for later years. The information in this dataset was public domain but cannot be used for commercial purposes. The data were likewise lifted directly from the GBD Study 2017.

The resulting database was analyzed using exploratory data analysis techniques to analyze trends over the years. Time-series graphs were the preferred method of presenting the data to compare the variables from each other visually.

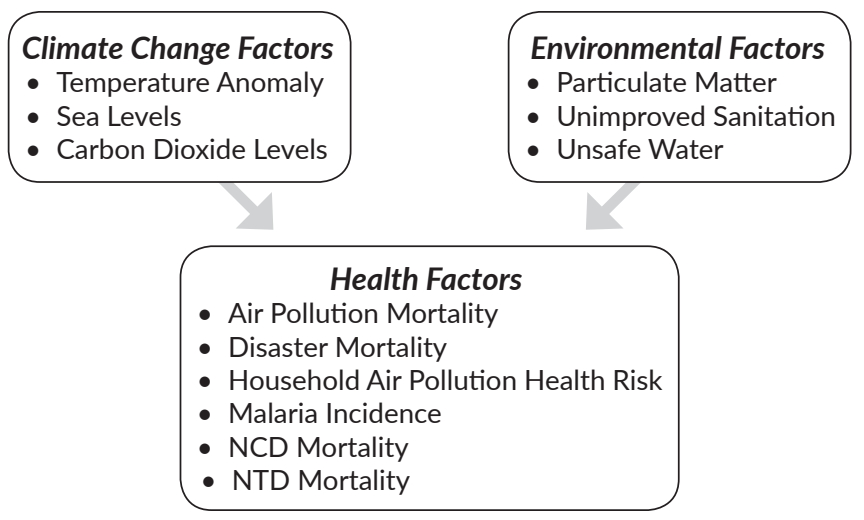

Figure 1. Conceptual framework of the relationship between climate change factors, environmental factors, and health.

Pearson Correlation analysis was performed to explore the linear relationship between health, climate, and environmental indicators. In particular, mean temperature anomaly, sea levels, carbon dioxide levels, particulate matter levels, the prevalence of unimproved sanitation, and prevalence of unsafe water were correlated against air pollution mortality, disaster mortality, household air pollution, health risk exposure value, malaria incidence, NCD mortality, and NTD mortality. This was performed to validate the relationships inferred visually in the graphs. (Figure 1)

The study was registered with the Research Grants Administration Office of the National Institutes of Health, University of the Philippines Manila.

\section{RESULTS}

The results of this study were presented into two categories - first, the health-related variables to climate change, and second, the health-related variables to environmental factors mediated by climate change.

\section{Health-Related Variables to Climate Change}

The distribution of some Health-related SDGs from the GBD Study 2017 is shown below (Figure 2). ${ }^{4}$ Since these are SDGs, and interventions were made to lower the prevalence drastically. This implies that without intervention, the trends could be increasing at a much higher rate. These were scaled as follows - air pollution mortality per 100,000 population; disaster mortality per 100,000 population; household air pollution health risk exposure value prevalence percent (\%); malaria incidence per 1,000 population; NCD mortality per 10,000 population; and percent (\%) NTD prevalence. The six health variables were chosen explicitly among the 41 predictors included in the study since these are climate-related, as suggested by the Lancet Countdown on health and climate change. ${ }^{14}$ (Figure 1 )

Air pollution mortality in the Philippines is defined as the age-standardized death rate attributable to household air pollution or ambient air pollution per 100,000 population. 
In the Philippines, the trend of air pollution mortality went downward from 105.745 in 1990 to 89.57 in 1999, then went on an upward trend again, peaking at 108.276 during 2011. It has since been on a downward trend.

On the other hand, household air pollution health risk in the Philippines is defined as the risk-weighted prevalence of household air pollution, measured by the SEV for household air pollution, in percent (\%).

The household air pollution prevalence in the Philippines was on a slow downward trend from $35.83 \%$ in 1990 to $28.51 \%$ in 2017 ; it was observed to be decreasing on an average of $0.83 \%$ every year.

Disaster mortality in the Philippines is defined as the death rate due to exposure to forces of nature per 1,000,000 population. Disaster mortality in the Philippines spikes randomly with the occurrence of natural disasters, in particular, super typhoons and earthquakes. The prominent peak during 2013 was due to typhoon Haiyan. The rise during 1995 was due to typhoon Angela (Rosing), which resulted in 882 fatalities. Lastly, the 1990 peak could be due to a 7.7 magnitude earthquake in Luzon.

Malaria incidence in the Philippines is defined as the age-standardized rate of malaria cases per 1000 population. Malaria incidence in the Philippines has decreased from 11.95 in 1990 to only 0.138 in 2017. It is falling on an average of $14.89 \%$ every year.

NCD mortality in the Philippines is defined as the age-standardized death rate due to cardiovascular disease, cancer, diabetes, and chronic respiratory disease in 30 to 70 , per 10,000 population. NCD mortality in the Philippines is constantly increasing from 41.99 in 1990 to 55.00 in 2016 ; it is growing on an average of $0.96 \%$ every year.

NTD mortality in the Philippines is defined as the agestandardized prevalence of the sum of 15 NTDs, in percent (\%). NTD mortality in the Philippines has decreased from 61.49 in 1990 to 27.99 in 2017, and it is slipping on an average of $2.6 \%$ every year. (Table 1 )

\section{Mean Temperature Anomalies}

The GISTEMP temperature analysis showing the values is the annual average of combined Land-Surface Air and Sea-Surface Water temperature anomalies, the deviations from the corresponding 1951-1980 means. ${ }^{5}$ The mean temperature for $1951-80$ was about $14^{\circ} \mathrm{C}$. In comparison, the lowest point was observed during 1992, where the average temperature anomaly was $0.23^{\circ} \mathrm{C}$ higher than the 1951 to 1980 means. This trend continuously increased until the latest data in 2016 , where the temperature anomaly was at $0.99^{\circ} \mathrm{C}$ higher than the 1951 to 1980 means. (Figure 3)

\section{Sea level (CSIRO)}

The loss of ice means higher sea levels. The CSIRO measures the global average absolute sea-level change. ${ }^{12}$ The highest recorded sea-level change, according to CSIRO, was during 2012 with 9.326 inches increase in sea level. It had increased by more than 3 inches from 6.23 in 1990. (Figure 4)

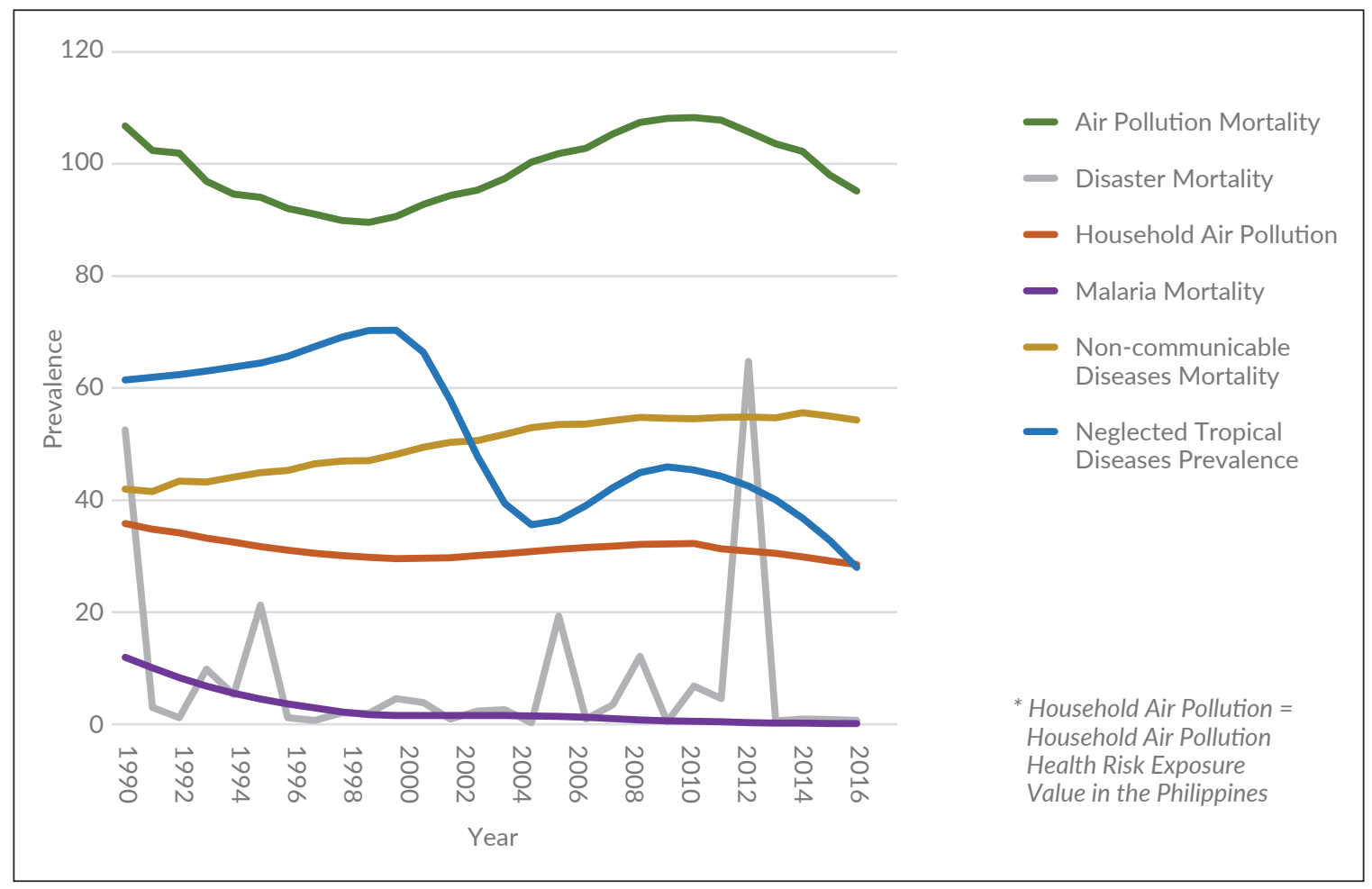

Figure 2. Prevalence of climate-related health issues in the Philippines. 


\section{Sea level (NOAA)}

This is the global average absolute sea-level change from 1880-2014 measured by the NOAA. ${ }^{7}$ The highest recorded sea-level change, according to NOAA, was during
2014 with 8.663 inches increase in sea level. It has increased by more than 2 inches from the 6.29 inches during 1993 . The difference between the measurements was due to the correction factor used by CSIRO and NOAA. (Figure 5)

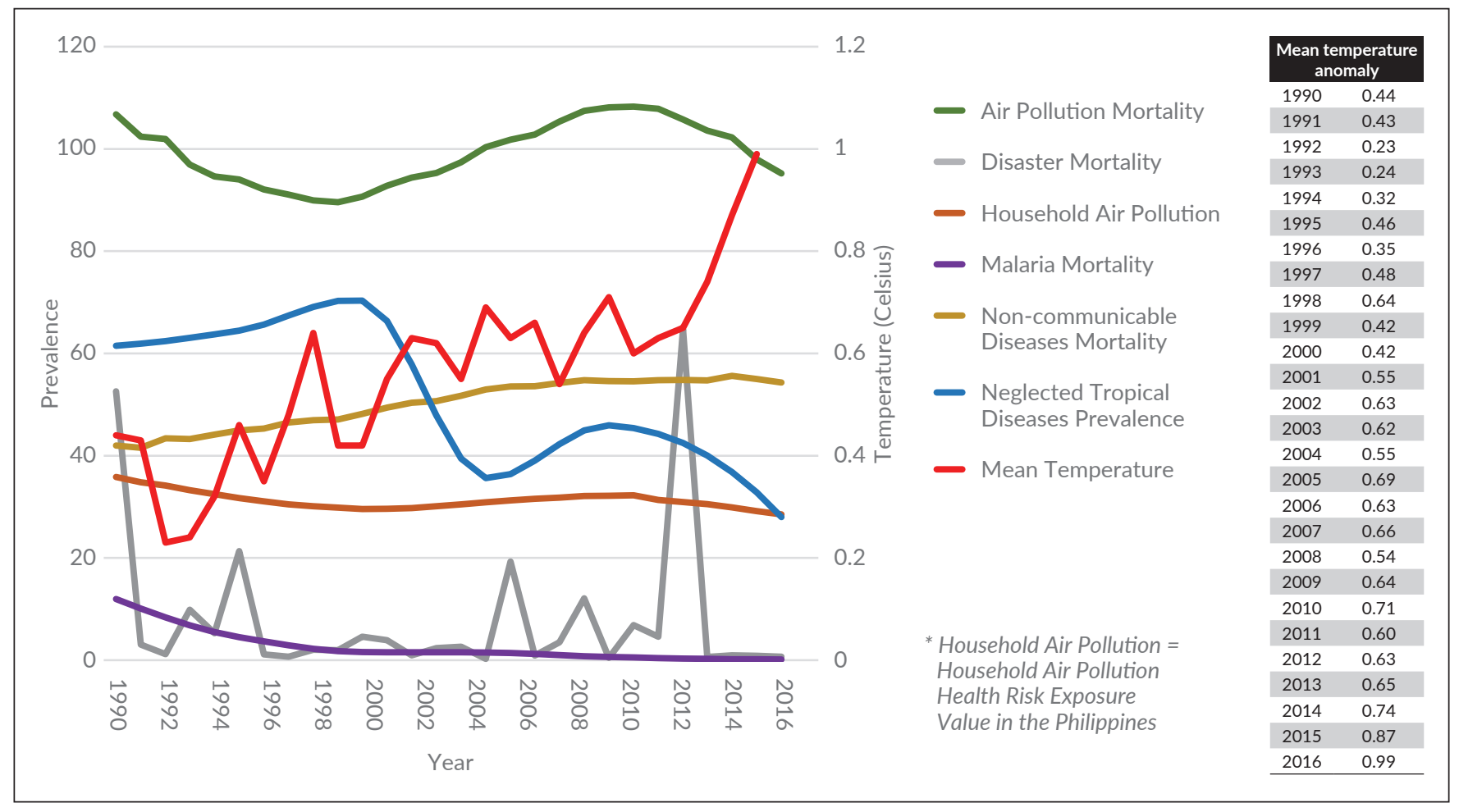

Figure 3. Temperature anomalies vs. prevalence of diseases in the Philippines.

Table 1. Correlation of climate change factors with various health variables

\begin{tabular}{|c|c|c|c|}
\hline Climate Change Factor & Health Variables & $\begin{array}{c}\text { Pearson Correlation } \\
\text { Coefficient }\end{array}$ & p-value \\
\hline \multirow[t]{4}{*}{ Mean Temperature Anomaly } & Household Air Pollution Health Risk Exposure Value in PH (estimate) & -0.519 & $<0.001$ \\
\hline & Malaria Incidence in $\mathrm{PH}$ (estimate) & -0.678 & $<0.001$ \\
\hline & Non-communicable Diseases Mortality in $\mathrm{PH}$ (estimate) & 0.817 & $<0.001$ \\
\hline & Neglected Tropical Diseases Prevalence in PH (estimate) & -0.743 & $<0.001$ \\
\hline \multirow[t]{4}{*}{ NOAA Adjusted Sea Level } & Air Pollution Mortality in $\mathrm{PH}$ (estimate) & 0.837 & $<0.001$ \\
\hline & Disaster Mortality in $\mathrm{PH}$ (estimate) & 0.248 & $<0.001$ \\
\hline & Malaria Incidence in $\mathrm{PH}$ (estimate) & -0.857 & $<0.001$ \\
\hline & Neglected Tropical Diseases Prevalence in PH (estimate) & -0.809 & $<0.001$ \\
\hline \multirow[t]{5}{*}{ Mean $\mathrm{CO}_{2}$ Global } & Air Pollution Mortality in $\mathrm{PH}$ (estimate) & 0.429 & $<0.001$ \\
\hline & Household Air Pollution Health Risk Exposure Value in PH (estimate) & -0.527 & $<0.001$ \\
\hline & Malaria Incidence in $\mathrm{PH}$ (estimate) & -0.793 & $<0.001$ \\
\hline & Non-communicable Diseases Mortality in PH (estimate) & 0.945 & $<0.001$ \\
\hline & Neglected Tropical Diseases Prevalence in PH (estimate) & -0.850 & $<0.001$ \\
\hline Mean $\mathrm{PM}_{2.5}$ in $\mathrm{PH}$ (estimate) & Household Air Pollution Health Risk Exposure Value in PH (estimate) & 0.406 & 0.03 \\
\hline \multirow{3}{*}{$\begin{array}{l}\text { Unimproved Sanitation in } \mathrm{PH} \\
\text { (estimate) }\end{array}$} & Household Air Pollution Health Risk Exposure Value in PH (estimate) & 0.515 & $<0.001$ \\
\hline & Malaria Incidence in $\mathrm{PH}$ (estimate) & 0.828 & $<0.001$ \\
\hline & Neglected Tropical Diseases Prevalence in PH (estimate) & 0.850 & $<0.001$ \\
\hline \multirow[t]{3}{*}{ Unsafe Water in PH (estimate) } & Household Air Pollution Health Risk Exposure Value in PH (estimate) & 0.858 & $<0.001$ \\
\hline & Malaria Incidence in PH (estimate) & 0.905 & $<0.001$ \\
\hline & Neglected Tropical Diseases Prevalence in PH (estimate) & 0.688 & $<0.001$ \\
\hline
\end{tabular}




\section{Mean $\mathrm{CO}_{2}$ Global}

This dataset is a global average of measurements over marine surface sites. The values are the annual mean $\mathrm{CO}_{2}$ mole fraction determined from daily averages. The data is reported as dry air mole fraction, defined as the number of carbon dioxide molecules divided by the number of all molecules in the air, including $\mathrm{CO}_{2}$ itself, after removing water vapor. The mole fraction is expressed as ppm. ${ }^{8}$

In 2017, $\mathrm{CO}_{2}$ levels were measured at $405 \mathrm{ppm}$. It has increased on an average of $0.5 \%$ every year since its 1990 reading at $353.98 \mathrm{ppm}$. Both $\mathrm{CO}_{2}$ estimates from Mauna Loa Observatory and marine surface sites seemed to negatively correlate with air pollution mortality and household air pollution estimates in the Philippines. (Figure 6)

\section{$\mathrm{PM}_{2.5}$ Levels}

This is the population-weighted mean level of fine particulate matter smaller than 2.5 microns in diameter in the Philippines. The US-EPA has created standards for classifying air quality. ${ }^{15}$ Currently, the standard for "good" $\mathrm{PM}_{2.5}$ levels is from $0-12 \mu \mathrm{g} / \mathrm{m}^{3}$, "moderate" is between $12.1 \mu \mathrm{g} / \mathrm{m}^{3}$ to $35.4 \mu \mathrm{g} / \mathrm{m}^{3}$, "unhealthy for sensitive groups" is between $35.5 \mu \mathrm{g} / \mathrm{m}^{3}$ to $55.4 \mu \mathrm{g} / \mathrm{m}^{3}$, "unhealthy" is between $55.5 \mu \mathrm{g} / \mathrm{m}^{3}$ to $150.4 \mu \mathrm{g} / \mathrm{m}^{3}$, "very unhealthy" is from $150.5 \mu \mathrm{g} / \mathrm{m}^{3}$ to $250.4 \mu \mathrm{g} / \mathrm{m}^{3}$. Hazardous is when $\mathrm{PM}_{2.5}$ levels are $250.5 \mu \mathrm{g} / \mathrm{m}^{3}$ and above. ${ }^{16} \mathrm{PM}_{2.5}$ levels in the Philippines was $22.116 \mu \mathrm{g} / \mathrm{m}^{3}$ in 1990 , increasing to $23.592 \mu \mathrm{g} / \mathrm{m}^{3}$ in 2010. Since then, $\mathrm{PM}_{2.5}$ levels have decreased, with $\mathrm{PM}_{2.5}$ levels in 2017 measured at $18.07 \mu \mathrm{g} / \mathrm{m}^{3}$. This is still under the "moderate" category as per EPA standards. The decline in $\mathrm{PM}_{2.5}$ levels seems to follow the same trend for Air Pollution mortality in PH, which peaked in 2011 then followed a decreasing trend since then. (Figure 7)

\section{Health-Related Variables to Environmental factors mediated by Climate Change}

\section{Unimproved sanitation prevalence}

This is the risk-weighted prevalence of populations using unsafe or unimproved sanitation as measured by the SEV for unsafe sanitation, in percent (\%). The trend was on a constant decrease, from $43.05 \%$ in 1990 to $11.81 \%$ in 2017 . (Figure 8)

The SDG for this indicator is to be equal to or less than $1 \%$ by 2030 . Malaria incidence and NTD prevalence seem to follow the same trend as Improved Sanitation.

\section{Unsafe water prevalence}

This is the risk-weighted prevalence of populations using unsafe or unimproved water sources, measured by the SEV for unsafe water, in percent (\%). The trend generally decreased from $59.89 \%$ in 1990 to $51.89 \%$ in 2003 , then increased to 54.05 in 2010, then down to $49 \%$ in 2017. (Figure 9) This might be a factor in the trend of NTD prevalence, NCD mortality, and malaria incidence.

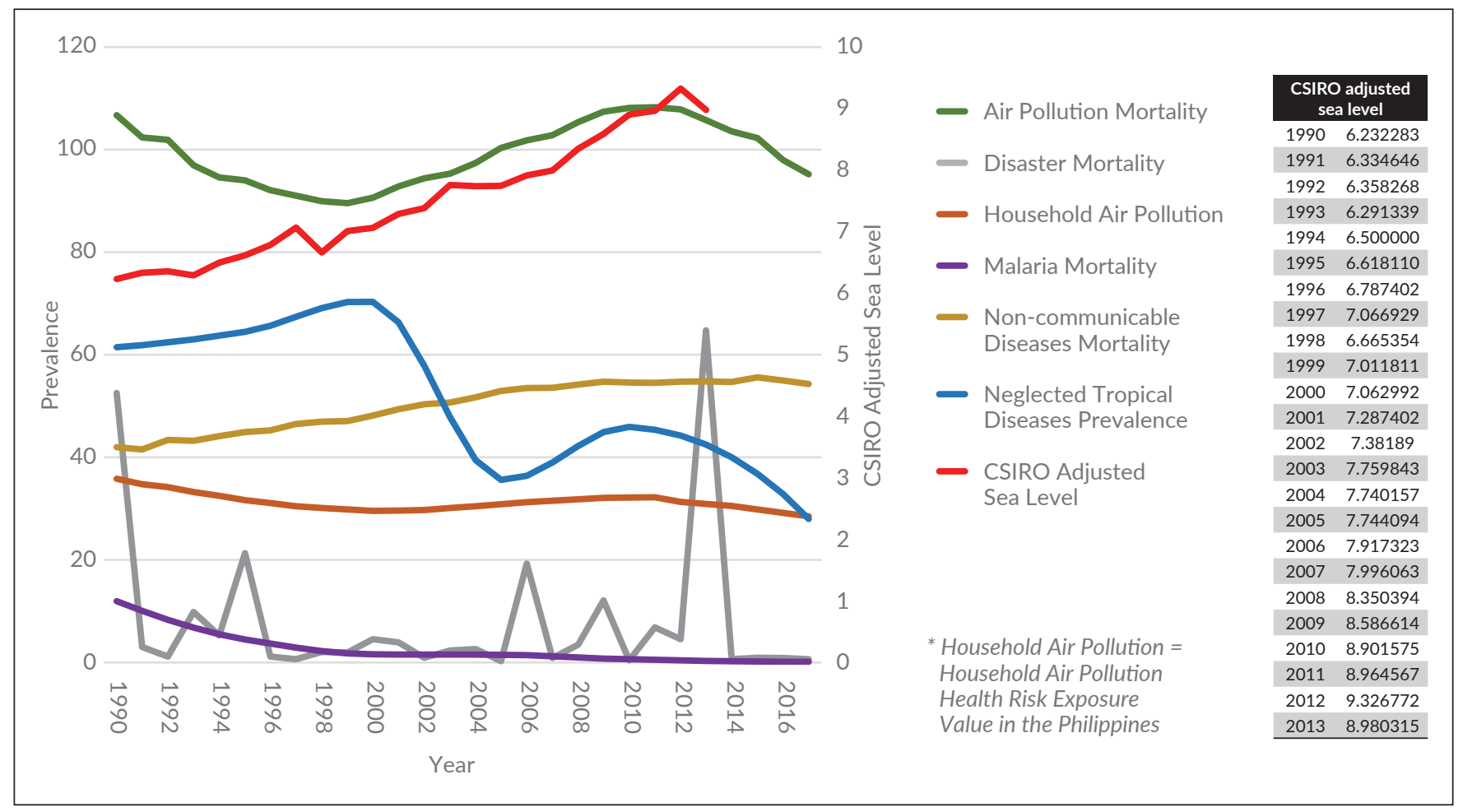

Figure 4. Sea Level (CSIRO) vs. prevalence of diseases in the Philippines. 


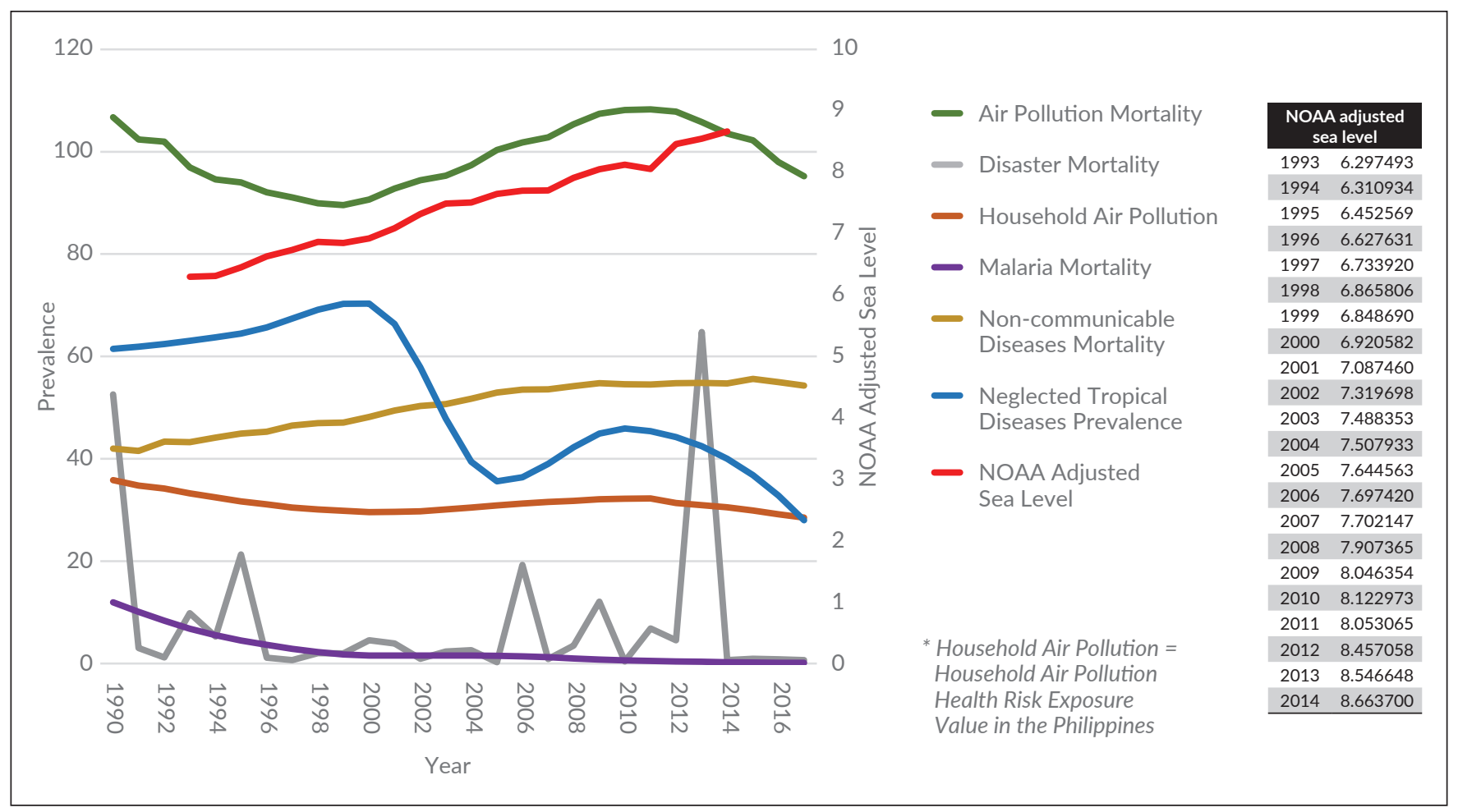

Figure 5. Sea Level (NOAA) vs. prevalence of diseases in the Philippines.

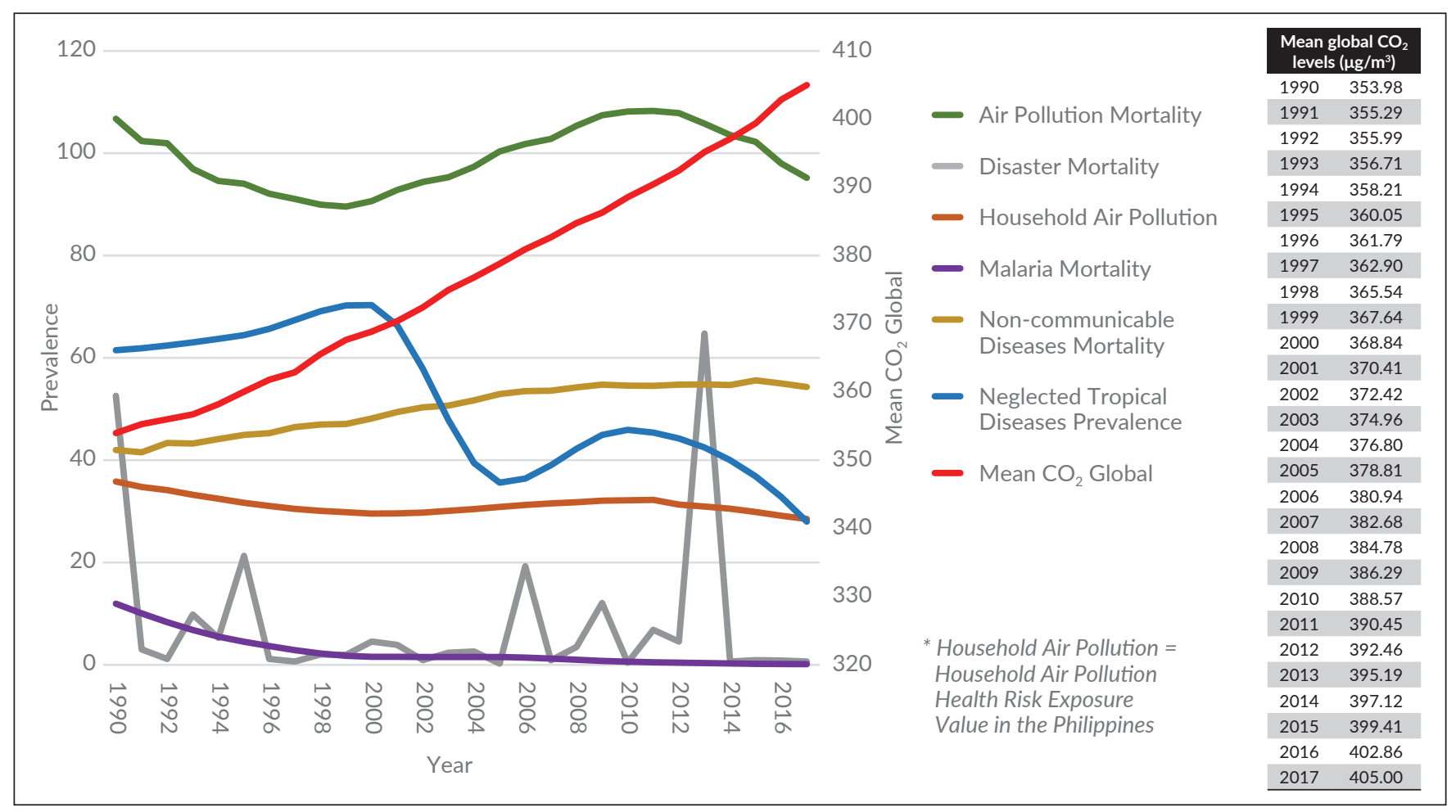

Figure 6. Global $\mathrm{CO}_{2}$ levels vs. prevalence of diseases in the Philippines. 


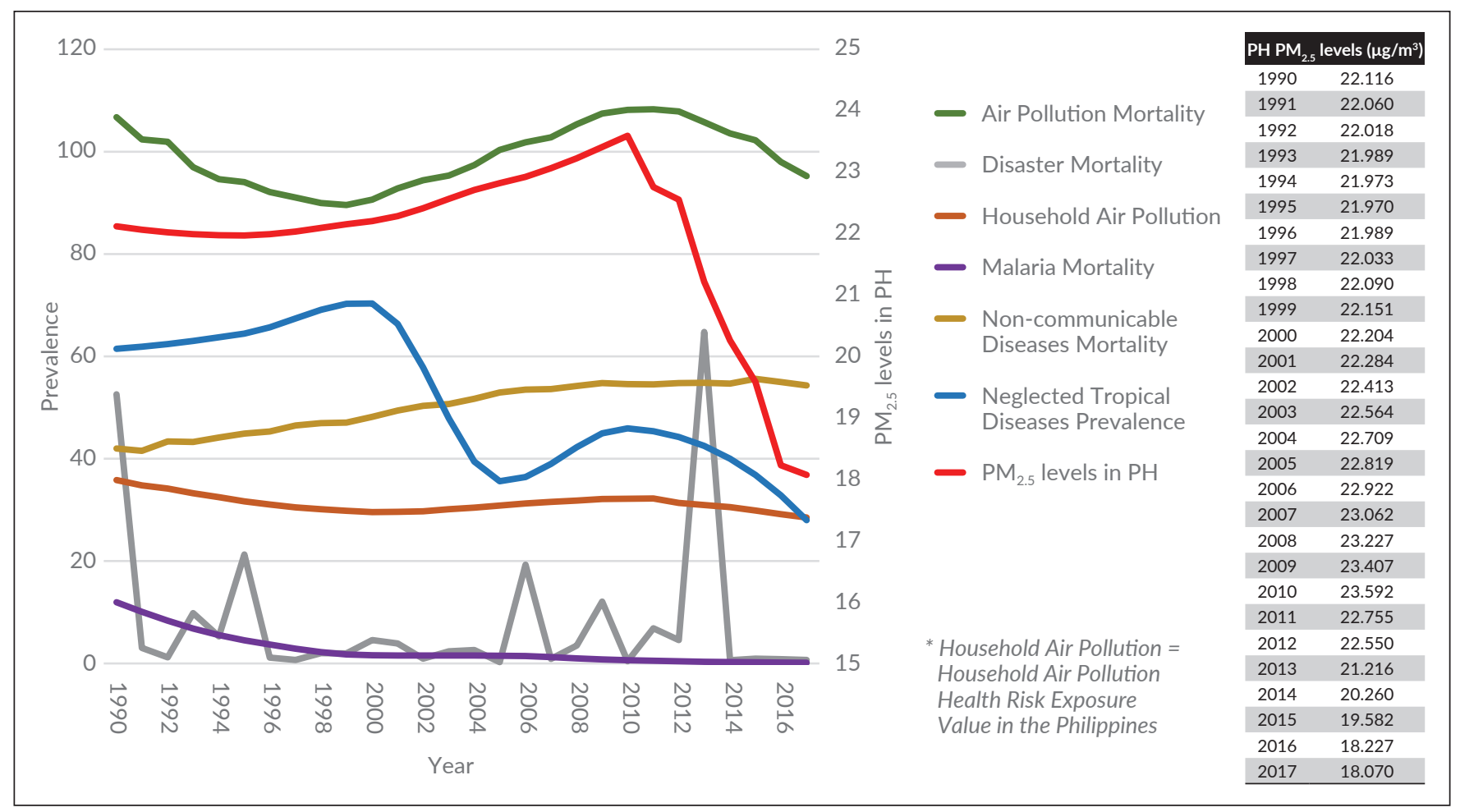

Figure 7. $\mathrm{PM}_{2.5}$ levels vs. prevalence of diseases in the Philippines.

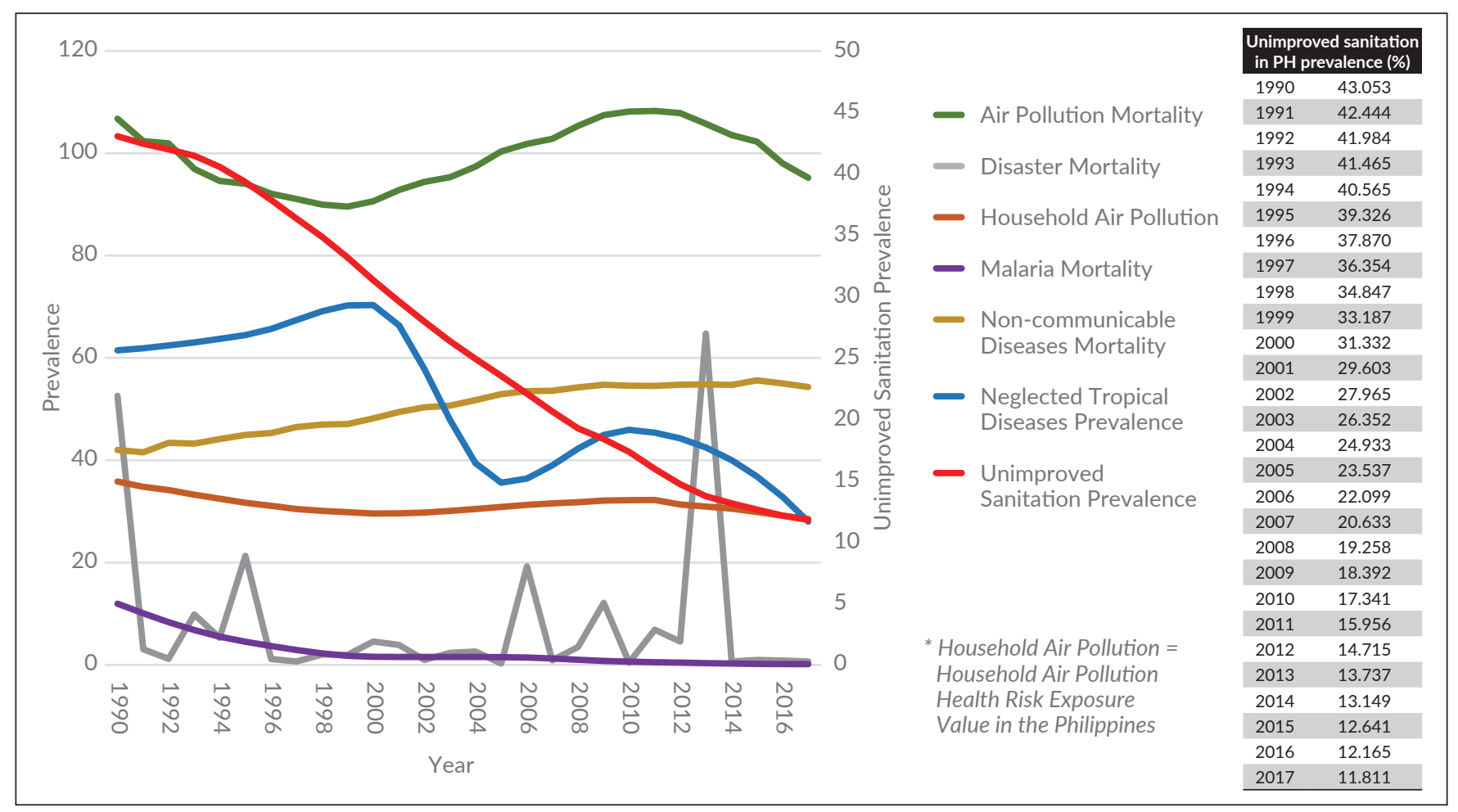

Figure 8. Unimproved sanitation prevalence v.s prevalence of diseases in the Philippines. 


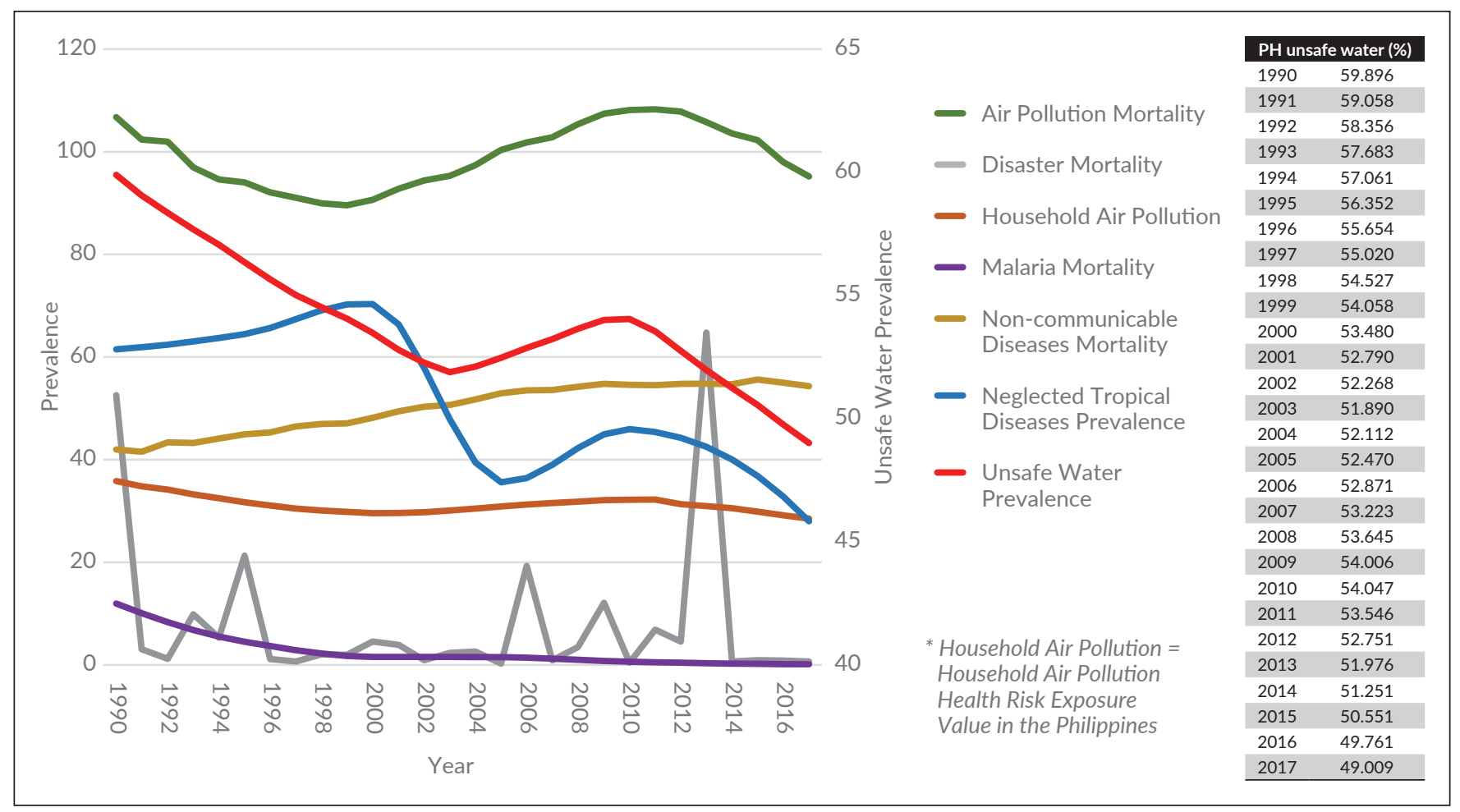

Figure 9. Unsafe water prevalence vs. prevalence of diseases in the Philippines.

Results of the study showed that household air pollution health risk exposure value prevalence significantly negatively correlated to mean temperature anomaly with a correlation coefficient of -0.519 ; significantly high and negatively correlated to malaria incidence; significantly high and positively correlated to NCD mortality; and highly negatively correlated with NTD mortality. (Table 2)

Meanwhile, NOAA adjusted sea level was significantly positively correlated with air pollution mortality and NCD. It is also negatively correlated with malaria incidence and NTD prevalence. (Table 2)

Air pollution mortality was also significantly positively correlated to the global $\mathrm{CO}_{2}$ with a correlation coefficient of 0.429 . Household air pollution health risk exposure value prevalence was significantly negatively correlated to the $\mathrm{CO}_{2}$ global levels with a correlation coefficient of -0.527 . It was also significantly high and negatively correlated to malaria incidence, significantly high and positively correlated to NCD mortality, and negatively correlated to NTD mortality. (Table 2)

The study results showed that household air pollution health risk exposure value prevalence was significantly positively correlated to the mean $\mathrm{PM}_{2.5}$ levels with a correlation coefficient of 0.406 . All other health variables were not significant. (Table 2)

Based on the data, household air pollution health risk exposure value prevalence was significantly and positively correlated to unimproved sanitation prevalence in the
Philippines with a correlation coefficient of 0.515 ; significantly high and positively correlated to malaria incidence, and significantly high and positively correlated NTD mortality in the Philippines. (Table 2)

Lastly, household air pollution health risk exposure value prevalence was significantly positively correlated to unsafe water prevalence in the Philippines with a correlation coefficient of 0.858 ; significantly high and positively correlated to malaria incidence, and significantly high and positively correlated to NTD mortality. (Table 2)

\section{DISCUSSION}

The Philippines is one of the most vulnerable countries where one can observe and project the impacts of climate change. ${ }^{15}$ The country's position in the Pacific leaves it in the path of multiple typhoons every year and climate change-induced temperature increases. Rainfall variability is considered most likely to have the most significant impact on coastal and low-lying urban areas. This also becomes a conducive environment for the breeding of vectors and transmission of diseases, malaria being one of them, thus vector-borne and heat-related diseases continue to increase in the country. ${ }^{15} \mathrm{NCD}$ are also influenced by changes in climate and exposure to air pollution.

The data in this study on climate change and health in the Philippines is a secondary analysis of variables already available in various large datasets mentioned earlier. This 
Table 1. The trend of selected health variables that are climate-related

\begin{tabular}{|c|c|c|c|c|c|c|}
\hline Year & $\begin{array}{c}\text { Air pollution } \\
\text { mortality per } \\
100,000 \text { population }\end{array}$ & $\begin{array}{l}\text { Disaster mortality } \\
\text { Per } 100,000 \\
\text { population }\end{array}$ & $\begin{array}{c}\text { Household air } \\
\text { pollution health } \\
\text { risk exposure value } \\
\text { prevalence percent (\%) }\end{array}$ & $\begin{array}{c}\text { Malaria incidence } \\
\text { per } 1000 \\
\text { population }\end{array}$ & $\begin{array}{c}\text { Non-communicable } \\
\text { diseases mortality } \\
\text { per } 10,000 \\
\text { population }\end{array}$ & $\begin{array}{c}\text { Neglected tropical } \\
\text { diseases mortality } \\
\text { prevalence percent } \\
(\%)\end{array}$ \\
\hline 1990 & 106.745 & 5.258 & 35.832 & 11.959 & 41.9959 & 61.490 \\
\hline 1991 & 102.386 & 0.304 & 34.787 & 10.078 & 41.5435 & 61.898 \\
\hline 1992 & 101.950 & 0.117 & 34.175 & 8.346 & 43.3823 & 62.419 \\
\hline 1993 & 96.956 & 0.985 & 33.242 & 6.809 & 43.2547 & 63.033 \\
\hline 1994 & 94.598 & 0.529 & 32.478 & 5.517 & 44.1345 & 63.718 \\
\hline 1995 & 94.034 & 2.131 & 31.684 & 4.514 & 44.9295 & 64.455 \\
\hline 1996 & 92.082 & 0.114 & 31.080 & 3.675 & 45.2985 & 65.657 \\
\hline 1997 & 91.054 & 0.067 & 30.482 & 2.887 & 46.4905 & 67.391 \\
\hline 1998 & 89.947 & 0.203 & 30.112 & 2.227 & 46.9566 & 69.112 \\
\hline 1999 & 89.572 & 0.196 & 29.834 & 1.766 & 47.0734 & 70.272 \\
\hline 2000 & 90.638 & 0.457 & 29.574 & 1.580 & 48.1599 & 70.327 \\
\hline 2001 & 92.809 & 0.390 & 29.620 & 1.562 & 49.4128 & 66.361 \\
\hline 2002 & 94.410 & 0.094 & 29.750 & 1.552 & 50.3386 & 57.855 \\
\hline 2003 & 95.320 & 0.236 & 30.112 & 1.545 & 50.6754 & 47.861 \\
\hline 2004 & 97.387 & 0.262 & 30.462 & 1.535 & 51.7310 & 39.428 \\
\hline 2005 & 100.343 & 0.026 & 30.867 & 1.518 & 52.9268 & 35.607 \\
\hline 2006 & 101.812 & 1.927 & 31.256 & 1.427 & 53.5168 & 36.403 \\
\hline 2007 & 102.816 & 0.090 & 31.558 & 1.236 & 53.5801 & 39.006 \\
\hline 2008 & 105.368 & 0.348 & 31.805 & 1.000 & 54.2237 & 42.243 \\
\hline 2009 & 107.435 & 1.211 & 32.105 & 0.777 & 54.7611 & 44.943 \\
\hline 2010 & 108.147 & 0.043 & 32.176 & 0.622 & 54.5775 & 45.932 \\
\hline 2011 & 108.276 & 0.686 & 32.236 & 0.521 & 54.5246 & 45.394 \\
\hline 2012 & 107.844 & 0.457 & 31.343 & 0.424 & 54.7609 & 44.263 \\
\hline 2013 & 105.772 & 6.477 & 30.947 & 0.335 & 54.8288 & 42.490 \\
\hline 2014 & 103.569 & 0.065 & 30.532 & 0.259 & 54.7012 & 40.025 \\
\hline 2015 & 102.253 & 0.094 & 29.876 & 0.198 & 55.6107 & 36.820 \\
\hline 2016 & 98.000 & 0.085 & 29.157 & 0.156 & 55.0069 & 32.826 \\
\hline 2017 & 95.203 & 0.067 & 28.514 & 0.138 & 54.3085 & 27.996 \\
\hline
\end{tabular}

study provides a new analysis of the GBD Study data to analyze SDGs. Here, the data was used to show the relationship between climate change indicators, environmental factors, and health factors. Notably, it focused on the Philippines, a country that is one of the most vulnerable to climate change.

Climate change is defined as the change in the mean weather patterns in the long term that has come to define various local, regional and global climates, and this is brought about by both human and natural-induced global temperature warming. ${ }^{17}$ On the other hand, global warming heating of Earth's climate system, in the long run, is brought about by natural and man-made causes. ${ }^{17}$ The natural causes of temperature changes are manifold- cyclical ocean patterns like El Niño, La Niña, Pacific Decadal Oscillation, volcanic activity, and changes in the Sun's energy output. ${ }^{17}$

Global warming associated with climate change is continuously rising. The years 2011 to 2020 were the warmest decade ever recorded. ${ }^{18}$ Human activities that affect global temperature are expected to increase the global warming rate by $0.2^{\circ} \mathrm{C}$ per decade. ${ }^{18}$ Since the pre-industrial era, it has been observed that the global temperature increased by $1.2^{\circ} \mathrm{C}$ in 2020 , as reported recently by the World Meteorological Organization (WMO).$^{19} \mathrm{~A} 2{ }^{\circ} \mathrm{C}$ increase in global temperature could adversely affect the environment and human health and well-being.

Climate change is characterized by increased global temperature and extreme weather events, melting glaciers and ice caps, rising sea levels, and increasing levels of greenhouse gases, amongst others. ${ }^{20}$

This study looked into the effects of climate change and its subsequent influence on human health in the Philippines using secondary data on climate change and health variables.

\section{Correlation of Mean Temperature Anomaly with Health Factors}

The study results showed that household air pollution health risk exposure value prevalence was significantly negatively correlated to mean temperature anomaly with a correlation coefficient of -0.519 . Indoor air quality (IAQ) is frequently measured through $\mathrm{CO}_{2}{ }^{21}$ This study in the Philippines showed a negative correlation $(-0.519)$ between household air pollution health risk exposure value and mean temperature anomaly, similar to studies in Korea and Turkey. The study in Korea investigated the relationship of carbon dioxide in kitchens, living rooms, and bedrooms against temperature among apartments in Seoul. ${ }^{22}$ They found that 
during cooling seasons with an outdoor temperature of above $32^{\circ} \mathrm{C}$ but less than $36^{\circ} \mathrm{C}$, there was a negative correlation of $\mathrm{CO}_{2}$ and temperature ${ }^{21}$ Meanwhile, the study in Turkey investigated the relationship of $\mathrm{CO}_{2}$ and particulate matter to temperature and showed a negative correlation of indoor $\mathrm{CO}_{2}$ (-0.409), $\mathrm{PM}_{10}(-0.324)$, and $\mathrm{PM}_{5.0}(-0.261)$ to indoor temperature during spring. ${ }^{23}$ These relationships may be attributed to ventilation. During increased temperatures, ventilations were essential to allow air circulation. This also caused $\mathrm{CO}_{2}$ and other air pollutants to decrease. ${ }^{23}$ More so, Yun et al. also found an observed increasing correlation between $\mathrm{CO}_{2}$ and indoor humidity during cooling seasons when the air conditioner is functioning. ${ }^{22}$ Closed environments lead to poor ventilation, which increases the concentration of air pollutants. This could also be further aggravated by inadequately cleaned air conditioners which can harbor harmful organisms. ${ }^{24}$

Mean temperature anomaly was found in this study to be significantly highly negatively correlated to malaria incidence. In a study in Bangladesh, temperatures and malaria incidence were positively correlated. ${ }^{25}$ More so, the risk of malaria mortality was found to increase beyond $26.3^{\circ} \mathrm{C}$ in Asia. ${ }^{26}$ This was because the increase in temperature resulted in faster reproduction of mosquitoes and that the $90 \%$ survival rate of these species was attributed to temperatures of $16^{\circ} \mathrm{C}$ to $36^{\circ} \mathrm{C} .^{25,27}$ This study in the Philippines found that mean temperature anomaly was significantly highly negatively correlated to malaria incidence. This result may be attributed to precipitation and rainfall in which temperatures in the Philippines seem to decrease instead of the summer season, similar to a study in Kenya wherein rainfall and precipitation were negatively correlated to malaria incidence. ${ }^{27}$ In addition, the study in Bangladesh also showed that the rainy season recorded to have the highest malaria cases. ${ }^{25}$ Precipitation between $20 \mathrm{~mm}$ and $80 \mathrm{~mm}$ showed an increased risk of mortality for malaria in a study conducted by Sewe et al. ${ }^{28}$ Malaria is also a common disease during rainy seasons in the Philippines. ${ }^{29}$

In this study focusing on the Philippines, the mean temperature anomaly was significantly highly positively correlated to NCD mortality. Scovronick et al. (2018) showed that there was an association between temperature and all-cause mortality. ${ }^{30}$ In the case of NCD, studies in Kenya showed that high temperatures have a significant positive relationship with NCD mortality. ${ }^{31}$ Bunker et al. (2017) also studied years life lost (YLL) from NCDs and found that exposure to high temperatures $\left(42.8^{\circ} \mathrm{C}\right)$ resulted in to increase in excess NCD-YLL of 7.39 for all ages. ${ }^{32} \mathrm{~A}$ study in Indonesia also showed that a high mean temperature above $29.5^{\circ} \mathrm{C}$ increases diabetes and cardiovascular diseases morbidity. ${ }^{33}$ These studies clearly showed that temperature affects NCD cases, in line with the current study results. For instance, increased temperature affects air quality by increasing concentrations of allergens, ozone, particulates, and dust, further aggravating respiratory diseases. ${ }^{34}$ Meanwhile, high temperatures could cause increased blood circulation and heart rate and decreased blood pressure which can lead to low cardiac outputs resulting in heat exhaustion, dehydration, and heatstroke. ${ }^{33}$

The study results found that mean temperature anomaly was significantly negatively correlated to NTD mortality in the Philippines. It showed that mean temperature anomaly was highly negatively correlated to NTD. Again, this may be attributed to precipitation, especially for vector-borne diseases such as dengue fever. A study in the Philippines showed that dengue fever and leptospirosis cases peaked during the wet season (June to November), specifically in September. ${ }^{35}$ This may be attributed to the rainy season when water pockets for mosquito breeding grounds are created. ${ }^{27}$ More so, flooding in some areas of the Philippines could further facilitate leptospirosis and other NTDs such as schistosomiasis, trachoma, soil-transmitted helminths, and guinea worm disease that is contracted through contaminated floodwaters. ${ }^{36}$ On the other hand, increasing dengue, chikungunya, leishmaniasis, and schistosomiasis cases in Europe and the USA were caused by warming temperatures and the changing precipitation patterns suitable for the survival of vectors. ${ }^{37}$

\section{Correlation of rising sea levels with health factors}

The study results showed that Air Pollution Mortality was significantly positively correlated to NOAA adjusted sea level with a correlation coefficient of 0.837 . Climate change causes sea levels to rise by increased temperature, causing glaciers and ice sheets to melt, causing ocean volume to expand due to warming waters, or both..$^{38}$ An increase in the temperature causes an increase of pollutants such as $\mathrm{O}_{3}$, $\mathrm{NO}_{2}$, particulates, and other allergens, which can aggravate or cause respiratory diseases. ${ }^{34,39}$ Hence, changing sea levels has an impact on air pollution mortality via increased temperature.

Since 1880, it has been reported that the global sea level has risen about 8 to 9 inches. ${ }^{38}$ Qin et al. found significant associations between respiratory mortality at high temperatures in a study in China ${ }^{40}$ In France, the relationship of heat-mortality was also explored by Pascal et al. ${ }^{41}$ It was found that ozone and $\mathrm{PM}_{10}$ mortality increased by $1.1 \%$ and $3 \%$ during summer, while in bouts of heatwaves, these risks can grow up to $14.1 \%$ for $\mathrm{PM}_{10}$ and $5.1 \%$ for ozone. ${ }^{41}$ Pollution increases the risk for heat mortality.

The results for NOAA adjusted sea level, although not significant, have a "poor positive correlation" with disaster mortality. Warmer sea surface temperatures through the increased global temperature brought about by climate change could result in stronger storms and wind speeds through the intense evaporation process. ${ }^{42,43}$

The rise in global temperature also caused a rise in sea levels, which could potentially cause coastal storms, storm surges, and flooding. ${ }^{38,42,44,45}$ This can be damaging to human health and society. For instance, Super Typhoon 
Haiyan (Yolanda)'s strength damaged properties and claimed at least 6,000 lives during its landfall in the Philippines, exacerbated by the rising sea levels and temperature. ${ }^{46,47}$ At sea surface temperatures of above $28^{\circ} \mathrm{C}$, typhoons could form; however, at its time of formation, the bodies of water surrounding the Philippines were recorded to be $30^{\circ} \mathrm{C}$ which was higher by about $1 / 2$ to $1^{\circ} \mathrm{C}$ than the average sea surface temperature from 1985-1993. More so, destructive storm surges of up to 5.2 meters from Typhoon Haiyan (Yolanda) were experienced in the Philippines, triggered by the global rise in sea levels. ${ }^{46}$

\section{Correlation of Global $\mathrm{CO}_{2}$ Levels with Health Factors}

Air pollution mortality is significantly positively correlated to Mean $\mathrm{CO}_{2} \mathrm{MLO}$ with a correlation coefficient of $0.427 . \mathrm{CO}_{2}$ is a known human metabolite, as well as a part of the Earth's atmosphere. ${ }^{48}$ The burning of fossil fuels and other related human activities has resulted in an average concentration of $\mathrm{CO}_{2}$ of about $400 \mathrm{ppm}$ in an ambient environment. ${ }^{48}$ Air pollution has been attributed to 400,000 premature deaths in Europe annually.

Diabetes, lung diseases, and cancer could be caused by long-term exposure to air pollutants. ${ }^{49}$ Air pollution was also attributed to higher death rates among COVID-19 patients. ${ }^{49}$ More so, exposures to $\mathrm{CO}_{2}$ at concentrations greater than $5 \%$ can cause hypercapnia and respiratory acidosis. At concentrations $>10 \%$, this can cause convulsions, coma, and death. ${ }^{50}$ It was also found that as a person ages, tolerance against $\mathrm{CO}_{2}$ also decreases $(p<0.0001){ }^{50}$

In this study in the Philippines, mean $\mathrm{CO}_{2}$ MLO levels were positively correlated to air pollution mortality. The study results showed that household air pollution health risk exposure value prevalence was significantly negatively correlated to mean $\mathrm{CO}_{2}$ global levels with a correlation coefficient of -0.527 .

IAQ is frequently measured through $\mathrm{CO}_{2}{ }^{21}$ The negative correlation of $\mathrm{CO}_{2}$ and household air pollution health risk exposure value prevalence may be confounded by temperature and ventilation, as seen in the study of Yun et al. (2020) and Argunhan and Aci (2018). ${ }^{22,23}$

The study results showed that global carbon dioxide measurements negatively correlated to malaria incidence and NTD in the Philippines. The negative correlation between global carbon dioxide levels and malaria incidence may be confounded by temperature. It was established that the increase in temperature also increased malaria mortality and incidence. ${ }^{25,26}$ Increased temperatures during summer or daytime resulted in lower $\mathrm{CO}_{2}$ concentrations in the air as plants respire. ${ }^{51}$ On the other hand, a study in India and Oman showed that $\mathrm{CO}_{2}$ concentration decreased during rainy seasons as it also allowed vegetation growth that took up $\mathrm{CO}_{2}{ }^{52,53}$ This may be the reason for the negative correlation of $\mathrm{CO}_{2}$, malaria incidence, and NTD in the Philippines as malaria, dengue fever, and leptospirosis are common diseases during the rainy season. ${ }^{29}$ In addition, schistosomiasis was also found to be influenced by rainfalls and flooding by which the latter can "facilitate human-parasite contact" ${ }^{44,55}$

This study in the Philippines showed that the global $\mathrm{CO}_{2}$ level was highly positively correlated to NCD mortality in the Philippines. Air pollution has been linked to cardiovascular and respiratory mortality. ${ }^{56,57} \mathrm{CO}_{2}$ specifically was associated with increased risk for chronic inflammation, bone demineralization and kidney calcification, respiratory acidosis, obesity and weight gain, and oxidative stress at $\mathrm{CO}_{2}$ concentrations of $<5,000 \mathrm{ppm}^{58}$ At $>10 \%$ concentrations, $\mathrm{CO}_{2}$ can cause death. ${ }^{50}$

\section{Correlation of $\mathrm{PM}_{2.5}$ with health factors}

The study results found that household air pollution health risk exposure value prevalence was significantly positively correlated to mean $\mathrm{PM}_{2.5}$ levels in Philippines with a correlation coefficient of 0.406 .

Particulate matter (PM) diameters of 2.5 and smaller are considered "fine particles" emitted from forest fires or created from gases emitted by power plants, industries, and vehicles. ${ }^{59}$ These particles can be found in smokes and hazes. ${ }^{59}$ A study in Poland showed that the concentration of outdoor $\mathrm{PM}_{2.5}$ influenced indoor concentrations, which was consistent with the results of this study in the Philippines. Indoor concentrations of $\mathrm{PM}_{2.5}$ may be affected by natural ventilation. ${ }^{60-62} \mathrm{~A}$ study in California showed that natural ventilation increased indoor levels of $\mathrm{PM}_{2.5}$ by 400 to 500\%; therefore, it may be beneficial to close windows and use air purifiers to reduce the concentrations of $\mathrm{PM}_{2.5}$ in households. ${ }^{61,62}$

The use of solid fuels also influences the concentration of $\mathrm{PM}_{2.5}$ in households, similar to the study of Ranathunga et al. among Sri Lankan households wherein it was found that increased $\mathrm{PM}_{2.5}$ concentrations were evident among families that use biomass compared to LPG and electricity as their cooking source (mean $1.09 \mathrm{mg} / \mathrm{m}^{3}$ vs. $0.30 \mathrm{mg} / \mathrm{m}^{3}$ ). ${ }^{63}$

\section{Correlation of Unimproved Sanitation with Health Factors}

Six out of ten (4.4 billion) people worldwide lack safe sanitation facilities. ${ }^{64}$ On the other hand, 3 out of 10 (2.1 billion) people still lack access to safe drinking water. ${ }^{64}$

In the Philippines, approximately 5 million people do not have access to safe drinking water, while the other 9 million lacks access to unimproved sanitation..$^{65}$ Access to safe drinking water and basic sanitation facilities is still a privilege among the wealthiest. People in urban households are more likely to access safe water and sanitation facilities than rural areas. ${ }^{64,66}$ The rapid pace of urbanization and the failure to keep up with the coverage levels on basic sanitation and safe drinking water services are to blame for the lack of access to these necessities. ${ }^{65,67}$ In addition, the lack of education regarding the environment, poor practices, and inconsistent waste management services are factors for poor 
environmental sanitation. ${ }^{68}$ Climate change also impacts peoples' sanitation and access to water through temperature extremes that cause flooding and droughts, which poses a threat for water pollution through chemical, biological, and radiological contamination. These can affect human health by further exacerbating disease spreading and disrupting sanitation systems. ${ }^{69}$

Furthermore, the study results showed that household air pollution health risk exposure value prevalence was significantly and positively correlated to unimproved sanitation prevalence in Philippines, with a correlation coefficient of 0.515. According to the latest 2011 Household Energy Consumption conducted by the Philippine Statistics Authority, the most commonly used fuel type of cooking of Filipino households are fuelwood (54.0\%), LPG (40.5\%), Charcoal (35.3\%), and Biomass (20.1\%) while kerosene is used by $2.1 \%$ of the households surveyed. ${ }^{70}$

Ritchie and Roser attributed the increasing air pollution mortality in low- to middle-income countries to indoor air pollution brought about by the use of solid fuels in cooking. ${ }^{71}$ Burning of solid fuel results in the emission of harmful components such as carbon monoxide (CO), particulates, polycyclic aromatic hydrocarbons, benzene, formaldehyde, and dioxin. ${ }^{72}$ True enough, a study in Sri Lanka showed that households that utilized biomass fuels as their primary cooking source showed higher concentrations of carbon monoxide (mean 2.77 ppm vs. $1.44 \mathrm{ppm}$ ) and $\mathrm{PM}_{2.5}$ (mean $1.09 \mathrm{mg} / \mathrm{m}^{3}$ vs. $0.30 \mathrm{mg} / \mathrm{m}^{3}$ ) as compared to households that used LPG or electricity as their cooking sources. ${ }^{63}$

Improper waste management also contributes to the burden of air pollution. Waste burning could also release air pollutants such as nitrogen oxides and sulfur dioxide, among others. ${ }^{73}$ Aside from the undesirable odor caused by open dumping, the decomposition of organic wastes contributes to the generation of greenhouse gases such as methane, carbon dioxide, and non-methane organic compounds. ${ }^{74,75}$ These could enter households and compromise the IAQ.

In addition, the study found that unimproved sanitation was significantly highly positively correlated to malaria incidence. The mortality of malaria was highly associated with environmental factors - temperature, rainfall, humidity, and sanitation. ${ }^{76}$

While most of the ecological factors affecting the prevalence of malaria are natural factors, sanitation is humaninduced. Some of which are overgrown bushes, littered wastes, potholes, empty water sachets, and receptacles that could provide breeding grounds for mosquitoes. ${ }^{77} \mathrm{~A}$ study in Cameroon showed that malaria prevalence was higher in bushy areas and areas with stagnant water. ${ }^{78}$ These areas were also associated with malaria infection. ${ }^{77}$ In developing countries, an unsanitary environment was strongly associated with malaria, which is consistent with the result of this study. ${ }^{79}$

The study results have also shown that unimproved sanitation was significantly positively correlated to NTD mortality in the Philippines. Sanitation also plays a crucial role in NTD morbidity and mortality; for instance, environmental factors such as overgrown bushes and tires with stagnant waters could provide breeding grounds for vectors carrying vector-borne NTDs such as dengue chikungunya and zika virus. ${ }^{77,80}$ In addition, improper waste disposal, such as the practice of open dumping, could facilitate and harbor flies, rodents, and mosquitoes' infestations. ${ }^{79}$

Hygiene practices are also factors for NTDs such as schistosomiasis, trachoma, and soil-transmitted helminths contracted through infected human wastes. ${ }^{81}$ In the Philippines, open defecation is still practiced by approximately 6 million Filipinos. In addition, 20 million people in the Philippines still lack the privilege of basic sanitation facilities. These are more common in poor households. ${ }^{64}$ This shows the importance of proper sanitation facilities and personal hygiene.

\section{Correlation of unsafe water with health factors}

The study results showed that household air pollution health risk exposure value prevalence was significantly positively correlated to hazardous water prevalence in the Philippines, with a correlation coefficient of 0.858 . The results may be confounded by improper waste disposal, especially because open dumping releases greenhouse gases such as methane and carbon dioxide. ${ }^{75}$ In addition, the decomposition process of this waste could contaminate the surrounding soil and bodies of water which could further degrade the quality of drinking waters. ${ }^{74}$ Another result found was that unsafe water prevalence is significantly highly positively correlated to malaria incidence. As discussed above, mosquitoes breed in unsanitary areas, especially in the regions that provide stagnant waters for the vectors to breed; specifically, the Anopheles genus that causes malaria breeds in dirty waters, subsequently affecting the morbidity and mortality of malaria cases. ${ }^{78,82} \mathrm{~A}$ study by Yang et al. showed that malaria risks increase with unprotected water $(\mathrm{aOR} 1.17$, 95\% CI 1.07-1.27, P = 0.001) and no sanitation facilities (OR 1.35, 95\% CI 1.24-1.47, P < 0.001) among children under five years of age which is consistent with the results of this study in the Philippines. ${ }^{83}$

Lastly, the study results showed that unsafe water prevalence is significantly high and positively correlated to NTD mortality in the Philippines. As mentioned above, vectors breed in stagnant waters, influencing the prevalence risk for NTDs such as dengue fever, chikungunya, and zika virus. ${ }^{78}$ Other NTDs such as schistosomiasis, trachoma, and soil-transmitted helminths can be contracted through infected human wastes. ${ }^{81}$ Unsanitary practices such as open defecation could contaminate soils and bodies water, and flooding could further facilitate the transmission of these diseases. ${ }^{84}$ This practice also compromises the quality of drinking waters, making it unsafe and could be a transmission platform for water-borne diseases such as cholera, diarrhea, dysentery, and NTDs such as guinea worm disease. ${ }^{84,85}$ The 
provision of safe water and sanitation could lessen the risk of NTD risks by $80 \%$ and prevent $9.1 \%$ of disease burden and $6.3 \%$ deaths globally. ${ }^{85}$ This is consistent with the results of this study.

\section{CONCLUSION}

This study summarizes data on how climate changes affect human health, environment, and diseases, thus, showing areas that need further research and exploration. As recordings of heat index increase and changes in other climate variables, there is a correlation with NCD, malaria, disaster, and NTD infection mortality. Unimproved sanitation and unsafe water prevalence were correlated with household air pollution and malaria, NCD, and NTD mortality.

With the evidence of the impact of climate change on health conditions, the urgency to focus on addressing these problems is present in this study. There is also a need to conduct further studies on the direct effects of climate change on health, especially with NCDs and NTDs, as these are currently the leading causes of mortality in the country. Further research may help in policymaking to target drivers of pollution which affect extreme climate changes.

The raw data were lifted directly from the sources and analyzed as is without further transformation. The strengths and weaknesses of the data are dependent on the database. Since these are established data from reputable scientific sources such as the World Health Organization and Lancet Countdown, the database is accurate.

\section{Statement of Authorship}

The author made the conceptualization of work, acquisition and analysis of data, drafting and revising, and final approval of the version to be published

\section{Author Disclosure}

The author declared no conflicts of interest.

\section{Funding Source}

This study was derived from a sub-topic of a study funded by the University of the Philippines Resilience Institute (UPRI).

\section{REFERENCES}

1. World Health Organization. Climate Change and Health [Internet]. Geneva: WHO; c2021 [updated 2018 Feb 01; cited 2021 Mar 18]. Available from: https://www.who.int/news-room/fact-sheets/detail/ climate-change-and-health.

2. Institute for Health Metrics and Evaluation. Findings from the Global Burden of Disease Study 2017 [Internet]. Seattle: Institute for Health Metrics and Evaluation; 2018 [cited 2021 Mar 18]. Available from: http://www.healthdata.org/sites/default/files/files/policy_report/2019/ GBD_2017_Booklet.pdf.

3. Watts N, Amann M, Arnell N, Ayeb-Karlsson S, Belesova K, Boykoff M, et al. The 2019 Report of the Lancet Countdown on Health and Climate Change: Ensuring that the Health of a Child
Born Today is Not Defined by a Changing Climate. The Lancet. 2019;394(10211):1836-78.

4. Global Burden of Disease Collaborative Network [dataset]. Global Burden of Disease Study 2017 (GBD 2017) Health-related Sustainable Development Goals (SDG) Indicators 1990-2030 [Internet]. 2018 [cited 2021 Mar 01]. Available from: http://ghdx.healthdata.org/ record/ihme-data/gbd-2017-health-related-sdgs-1990-2030.

5. GISTEMP Team [dataset]. GISS Surface Temperature Analysis (GISTEMP), version 4. 2021 [cited 2021 Mar 01]. Available from: https://data.giss.nasa.gov/gistemp/.

6. Epa.gov [Internet]. Washington (DC): United States Environmental Protection Agency; c2021 [cited 2021 Mar 01]. Available from: https://www.epa.gov/.

7. National Oceanic and Atmospheric Administration [dataset]. Climate Change: Global Sea Level. 2021 Jan 25 [cited 2021 Mar 01]. Available from: https://www.climate.gov/news-features/understanding-climate/ climate-change-global-sea-level.

8. Global Monitoring Laboratory - National Oceanic and Atmospheric Administration [dataset]. Trends in Atmospheric Carbon Dioxide. n.d. [cited 2021 Mar 01]. Available from: https://gml.noaa.gov/ccgg/ trends/global.html.

9. Ipcc.ch [Internet]. Geneva: Intergovernmental Panel on Climate Change; c2021 [cited 2021 Mar 01]. Available from: https://www.ipcc. $\mathrm{ch} /$.

10. Nsstc.uah.edu [Internet]. Hunstville: The National Space Science \& Technology Center @ UAHuntsville; c2016 [cited 2021 Mar 01]. Available from: https://www.nsstc.uah.edu/nsstc/.

11. Data.gov [Internet]. [cited 2021 Mar 01]. Available from: https:// www.data.gov/.

12. Commonwealth Scientific and Industrial Research Organisation [dataset]. Sea Level Rise. n.d. [cited 2021 Mar 01]. Available from: https://www.cmar.csiro.au/sealevel/sl_hist_last_decades.html.

13. Ucar.edu [Internet]. Boulder: University Corporation for Atmospheric Research; c2021 [cited 2021 Mar 01]. Available from: https://www. ucar.edu/.

14. Watts N, Amann M, Arnell N, Ayeb-Karlsson S, Belesova K, Berry H, et al. The 2018 Report of the Lancet Countdown on Health and Climate Change: Shaping the Health of Nations for Centuries to Come. The Lancet. 2017 Dec 08;392(10163):2479-2514.

15. United States Environmental Protection Agency. Revised Air Quality Standards for Particle Pollution and Updates to the Air Quality Index (AQI) [Internet]. 2012 [cited 2021 Mar 03]. Available from: https://www.epa.gov/sites/default/files/2016-04/documents/2012_ aqi_factsheet.pdf.

16. Cruz RVO, Aliño PM, Cabrera OC, David CPC, David LT, Lansigan FP, et al. 2017 Philippine Climate Change Assessment: Impacts, Vulnerabilities and Adaptation [Internet]. Pasig City: The Oscar M. Lopez Center for Climate Change Adaptation and Disaster Risk Management Foundation, Inc. and Climate Change Commission; 2017 [cited 2021 Mar 18]. Available from: https://climate.gov.ph/files/ PhilCCA-WG2.pdf.

17. Global Climate Change - National Aeronautics and Space Administration [Internet]. California: National Aeronautics and Space Administration; c2021 [cited 2021 Aug 09]. Overview: Weather, Global Warming and Climate Change; [about 5 screens]. Available from: https://climate.nasa.gov/resources/global-warming-vs-climatechange/.

18. European Commission [Internet]. Brussels: European Commission; c2021 [cited 2021 Aug 09]. Causes of Climate Change; [about 3 screens]. Available from: https://ec.europa.eu/clima/change/causes_en.

19. UN Environment Programme. Alarming Rise in Global Temperatures [Internet]. Nairobi: UNEP; c2021 [update 2021 Feb 04; cited 2021 Aug 09]. Available from: https://www.unep.org/news-and-stories/ story/alarming-rise-global-temperatures.

20. National Geographic [Internet]. Washington: National Geographic Partners, LLC.; c2015-2021 [cited 2021 Aug 19]. Effect of Global Warming; [about 3 screens]. Available from: https://www. nationalgeographic.com/environment/article/global-warming-effects. 
21. Gao Y, Chen F, Wang Z. The Distribution and Influential Factors of PM2.5 and CO2 in Urban Rail Carriages. Indoor Built Environ. 2019 Apr 20;28(10):1383-95.

22. Yun H, Yang J, Lee BH, Kim J, Sohn J. Indoor Thermal Environment Long-Term Data Analytics Using IoT Devices in Korean Apartments: A Case Study. Int J Environ Res Public Health. 2020 Oct 8;17:7334.

23. Argunhan Z, Aci AS. Statistical Evaluation of Indoor Air Quality Parameters in Classrooms of a University. Adv Meteorol. 2018 Mar 18;2018:4391579.

24. Apte K, Salvi S. Household Air Pollution and Its Effects on Health. F1000Res. 2016 Oct 28;5:F1000 Faculty Rev-2593.

25. Chowdhury FR, Ibrahim QSU, Bari MS, Alam MMJ, Dunachie SJ, Rodriguez-Morales AJ, et al. The Association between Temperature, Rainfall and Humidity with Common Climate-sensitive Infectious Diseases in Bangladesh. PLoS One. 2018 Jun 21;13(6):e0199579. PubMed PMID: 29928056.

26. Dasgupta S. Burden of Climate Change on Malaria Mortality. Int J Hyg Environ Health. 2018 Jun;221(5):782-91.

27. Okunlola OA, Oyeyemi OT. Spatio-temporal Analysis of Association between Incidence of Malaria and Environmental Predictors of Malaria Transmission in Nigeria. Sci Rep. 2019 Nov 25;9(1):17500. PubMed PMID: 31767899.

28. Sewe MO, Ahlm C, Rocklöv J. Remotely Sensed Environmental Conditions and Malaria Mortality in Three Malaria Endemic Regions in Western Kenya. PLoS One. 2016 Apr 26;11(4):e0154204. PubMed PMID: 27115874

29. Roxas PAV. DOH: Prepare for Common Rainy Season Diseases [Internet]. Makati City: INQUIRER.NET; c1997-2021 [updated 2019 Jun 07; cited 2021 Aug 08]. Available from: https://newsinfo. inquirer.net/1127719/doh-prepare-for-common-rainy-seasondiseases.

30. Scovronick N, Sera F, Acquaotta F, Garzena D, Fratianni S, Wright CY, Gasparrini A. The Association between Ambient Temperature and Mortality in South Africa: A Time-series Analysis. Environ Res. 2018 Feb;161:229-35.

31. Egondi T, Kyobutungi C, Kovats S, Muindi K, Ettarh R, Rocklöv J. Time-series Analysis of Weather and Mortality Patterns in Nairobi's Informal Settlements. Glob Health Action. 2012 Nov 23;5:23-32.

32. Bunker A, Sewe MO, Sié A, Rocklöv J, Sauerborn R. Excess Burden of Non-communicable Disease Years of Life Lost from Heat in Rural Burkina Faso: a Time Series Analysis of the Years 2000-2010. BMJ Open. 2017 Nov 4;7(11):e018068. PubMed PMID: 29102994.

33. Fritz, Manuela (2021): Temperature and Non-communicable Diseases: Evidence from Indonesia's Primary Health Care System, Passauer Diskussionspapiere - Volkswirtschaftliche Reihe, No. V-84-21, Universität Passau, Wirtschaftswissenschaftliche Fakultät, Passau.

34. Amegah AK, Rezza G, Jaakkola JJ. Temperature-related Morbidity and Mortality in Sub-Saharan Africa: A Systematic Review of the Empirical Evidence. Environ Int. 2016 May;91:133-49.

35. Sumi A, Telan EFO, Chagan-Yasutan H, Piolo MB, Hattori T, Kobayashi N. Effect of Temperature, Relative Humidity and Rainfall on Dengue Fever and Leptospirosis Infections in Manila, the Philippines. Epidemiol Infect. 2017;145:78-86.

36. Easton A. Leptospirosis in Philippine Floods. BMJ. 1999 Jul 24;319(7204):212.

37. Tidman R, Abela-Ridder B, de Castañeda RR. The Impact of Climate Change on Neglected Tropical Diseases: a Systematic Review. Trans R Soc Trop Med Hyg. 2021 Jan 28;115(2):147-68.

38. Lindsey R. Climate Change: Global Sea Level [Internet]. 2021 Jan 25 [cited 2021 Aug 07]. Available from: https://www.climate.gov/newsfeatures/understanding-climate/climate-change-global-sea-level.

39. Kalisa E, Fadlallah S, Amani M, Nahayo L, Habiyaremye G. Temperature and air pollution relationship during heatwaves in Birmingham UK [Internet]. n.d. Available from: https://eprints. lancs.ac.uk/id/eprint/127503/1/Pure_ID_244951877_Temperature_ and_air_pollution_relationship_during_heatwaves_in_Birmingham UK.pdf.

40. Qin RX, Xiao C, Zhu Y, Li J, Yang J, Gu S, et al. The Interactive Effects between High Temperature and Air Pollution on Mortality:
A Time-series Analysis in Hefei, China. Sci Total Environ. 2017 Jan 1;575:1530-7.

41. Pascal M, Wagner V, Alari A, Corso M, Le Terte A. Extreme Heat and Acute Air Pollution Episodes: A Need for Joint Public Health Warnings?. Atmos Environ. 2021 Mar 15;249:118249.

42. Center for Climate and Energy Solutions [Internet]. Arlington County: Center for Climate and Energy Solutions; c2021 [cited 2021 Aug 14]. Hurricanes and Climate Change; [about 3 screens]. Available from: https://www.c2es.org/content/hurricanes-and-climate-change/.

43. Environmental Defense Fund [Internet]. New York City: Environmental Defense Fund; c2021 [cited 2021 Aug 14]. Available from: https://www.edf.org/climate/how-climate-change-makes-hurricanesmore-destructive.

44. Mimura N. Sea-level Rise Caused by Climate Change and Its Implications for Society. Proc Jpn Acad Ser B Phys Biol Sci. 2013; 89(7):281-301.

45. Arns A, Wahl T, Dangendorf S, Jensen J. The Impact of Sea-level Rise on Storm Surge Water Levels in Northern Part of the German Bight. Coast Eng. 2015 Feb;96:118-31.

46. Climate Nexus [Internet]. New York: Climate Nexus; c2021 [cited 2021 Aug 14]. Typhoon Haiyan; [about 1 screen]. Available from: https://climatenexus.org/climate-news-archive/extreme-weather/ typhoon-haiyan/.

47. Kinghorn J. Why The Tacloban Storm Surge Was So Devastating [Internet]. Boston: AIR Worldwide; c2000-2021 [updated 2018 Nov 08; cited 2021 Aug 14]. Available from: https://www.air-worldwide. com/blog/posts/2018/11/why-storm-surge-was-so-devastating-fortacloban/.

48. Tran VV, Park D, Lee YC. Indoor Air Pollution, Related Human Diseases, and Recent Trends in the Control and Improvement of Indoor Air Quality. Int J Environ Res Public Health. 2020 Apr 23;17(8):2927.

49. Abnett K. 1 in 8 deaths in Europe are Linked to Pollution, Says EU [Internet]. Cologny: World Economic Forum; c2021 [updated 2020 Sep 09; cited 2021 Aug 10]. Available from: https://www.weforum. org/agenda/2020/09/carbon-emissions-european-union-health/.

50. Permentier K, Vercammen S, Soetaert S, Schellemans C. Carbon Dioxide Poisoning: a Literature Review of an Often Forgotten Cause of Intoxication in the Emergency Department. Int J Emerg Med. 2017 Dec;10(1):14.

51. Copernicus. Carbon Dioxide Levels are Rising: Is it Really that Simple?. Brussels: European Commission; c2021 [updated 2019 May 28; cited 2021 Aug 10]. Available from: https://atmosphere.copernicus. eu/carbon-dioxide-levels-are-rising-it-really-simple.

52. Tiwari YK, Revadekar JV, Kumar R. Variations in Atmospheric Carbon Dioxide and its Association with Rainfall and Vegetation Over India. Atmos Environ. 2013 Apr;68:45-51.

53. Golkar F, Al-Wardy M, Saffari SF, Al-Aufi K, Al-Rawas G. Using OCO-2 Satellite Data for Investigating the Variability of Atmospheric $\mathrm{CO} 2$ Concentration in Relationship with Precipitation, Relative Humidity, and Vegetation over Oman. Water. 2019 Dec 27;12:101.

54. Gordon CA, Kurscheid J, Williams GM, Clements ACA, Li Y, Zhou $\mathrm{XN}$, et al. Asian Schistosomiasis: Current Status and Prospects for Control Leading to Elimination. Trop Med Infect Dis. 2019 Feb 26;4(1):40.

55. Leonardo L, Rivera P, Saniel O, Villacorte E, Lebanan MA, Crisostomo B, et al. A National Baseline Prevalence Survey of Schistosomiasis in the Philippines Using Stratified Two-step Systematic Cluster Sampling Design. J Trop Med. 2012;2012:936128. PubMed PMID: 22518170.

56. Dehghan A, Khanjani N, Bahrampour A, Goudarzi G, Yunesian M. The Relation between Air Pollution and Respiratory Deaths in Tehran, Iran- Using Generalized Additive Models. BMC Pulm Med. 2018 Mar 20;18(1):49.

57. Xia SY, Huang DS, Jia H, Zhao Y, Li N, Mao MQ, et al. Relationship between Atmospheric Pollutants and Risk of Death Caused by Cardiovascular and Respiratory Diseases and Malignant Tumors in Shenyang, China, from 2013 to 2016: an ecological research. Chin Med J (Engl). 2019 Oct 5;132(19):2269-77. 
58. Jacobson TA, Kler JS, Hernke MT, Braun RK, Meyer KC, Funk WE. Direct Human Health Risks of Increased Atmospheric Carbon Dioxide.

59. United States Environmental Protection Agency [Internet]. New England: EPA; c2021 [cited 2021 Aug 11]. What is Particulate Matter?; [about 1 screen]. Available from: https://www3.epa.gov/ region1/eco/uep/particulatematter.html.

60. Ścibor M, Balcerzak B, Galbarczyk A, Targosz N, Jasienska G. Are We Safe Inside? Indoor Air Quality in Relation to Outdoor Concentration of PM10 and PM2.5 and to Characteristics of Homes. Sustain Cities Soc. 2019 Jul;48:101537.

61. Martins NR, da Graça GC. Impact of Outdoor PM2.5 on Natural Ventilation Usability in California's Nondomestic Buildings. Appl Energy. 2017 Mar 1;189:711-24.

62. Huang K, Song J, Feng G, Chang Q, Jiang B Wang J, et al. Indoor Air Quality Analysis of Residential Building in Northeast China Based on Field Measurements and Longtime Monitoring. Build Environ. 2018 Oct;144:171-83.

63. Ranathunga N, Perera P, Nandasena S, Sathiakumar N, Kasturiratne A, Wickremasinghe R. Effect of Household Air Pollution due to Solid Fuel Combustion on Childhood Respiratory Diseases in a Semi-urban Population in Sri Lanka. BMC Pediatr. 2019 Sep 2;19(1):306.

64. United Nations Children's Fund. Two Billion People Lack Safe Drinking Water, More than Twice Lack Safe Sanitation [Internet]. Mandaluyong City: UNICEF Philippines; c2021 [updated 2017 Jul 17; cited 2021 Aug 13]. Available from: https://www.unicef.org/ philippines/press-releases/two-billion-people-lack-safe-drinkingwater-more-twice-lack-safe-sanitation.

65. Water.org [Internet]. Kansas: Water.org; c2021 [cited 2021 Aug 13]. Philippines'Water and Sanitation Crisis; [about 2 screens]. Available from: https://water.org/our-impact/where-we-work/philippines/.

66. Tuyet-Hanh TT, Lee JK, Oh J, Van Minh H, Ou Lee C, Hoan le T, et al. Household Trends in Access to Improved Water Sources and Sanitation Facilities in Vietnam and Associated Factors: Findings from the Multiple Indicator Cluster Surveys, 2000-2011. Glob Health Action. 2016 Feb 29;9:29434. PubMed PMID: 26950563.

67. World Health Organization and United Nations Children's Fund. Meeting the MDG Drinking Water and Sanitation Target: the Urban and Rural Challenge of the Decade [Internet]. Geneva: World Health Organization and UNICEF; 2006 [cited 2021 Aug 13]. Available from: https://www.who.int/water_sanitation_health/ monitoring/jmpfinal.pdf.

68. Abdulrasaq Q, Suleiman Y, Olamiposi A. Factors Contributing to Poor Environmental Sanitation as Perceived by Health Education Students in Ilorin South Local Government Area 1 [Internet]. 2019 Aug [cited 2021 Aug 13]. Available from: https://www.researchgate. net/publication/337658565_FACTORS_CONTRIBUTING_ TO_POOR_ENVIRONMENTAL_SANITATION_AS_ PERCEIVED_BY_HEALTH_EDUCATION_STUDENTS_IN_ILORIN_SOUTH_LOCAL_GOVERNMENT_AREA_1.

69. United Nations. Climate Change and the Human Rights to Water and Sanitation [Internet]. n.d. [cited 2021 Aug 13]. Available from: https://www2.ohchr.org/english/issues/water/iexpert/docs/ climatechange_hrtws.pdf.

70. National Statistics Authority. 2011 Household Energy Consumption Survey [Internet]. Quezon City: National Statistics Authority; 2011 [cited 2021 Aug 12]. Available from: http://www.psa.gov.ph/sites/ default/files/HECS\%202011.pdf.

71. Ritchie H, Roser M. Air Pollution [Internet]. Oxford: Our World In Data; c2021 [updated 2019 Nov; cited 2021 Aug 08]. Available from: https://ourworldindata.org/air-pollution\#who-is-most-affected-byair-pollution.
72. Smith KR, Pillarisetti A. Household Air Pollution from Solid Cook Fuels and Its Effects on Health. In: Mock CN, Nugent R, Kobusingye $\mathrm{O}$, et al., editors. Injury Prevention and Environmental Health. 3rd edition. Washington (DC): The International Bank for Reconstruction and Development / The World Bank; 2017 Oct 27. Chapter 7. Available from: https://www.ncbi.nlm.nih.gov/books/ NBK525225/ doi: 10.1596/978-1-4648-0522-6_ch7.

73. Wisconsin Department of Natural Resources [Internet]. Madison: Wisconsin Department of Natural Resources; c2021 [cited 2021 Aug 3]. ENVIRONMENTAL AND HEALTH IMPACTS OF OPEN BURNING; [about 2 screens]. Available from: https://dnr.wisconsin. gov/topic/OpenBurning/Impacts.html.

74. Etea T, Girma E, Mamo K. Risk Perceptions and Experiences of Residents Living Nearby Municipal Solid Waste Open Dumpsite in Ginchi Town, Ethiopia: A Qualitative Study. Risk Manag Healthc Policy. 2021 May 18;14:2035-44.

75. Rafiq A, Rasheed A, Arslan C, Tallat U, Siddique M. Estimation of Greenhouse Gas Emissions from Muhammad Wala Open Dumping Site of Faisalabad, Pakistan. Geology, Ecology, And Landscapes. 2018;2(1):45-50.

76. Abdullahi AA, Abubakar AD. Why It Is Difficult to Eradicate Malaria in Sub-Saharan Africa. Perspect Glob Dev Technol. 2019;18:269-85.

77. Okoye CO, Nwachukwu MC. Human-Induced Environmental Factors and Mosquito Breeding in Enugu Urban-Nigeria. Am J Eng Res. 2014;3(5):57-63.

78. Nyasa RB, Fotabe EL, Ndip RN. Trends in Malaria Prevalence and Risk Factors Associated with the Disease in Nkongho-mbeng; a Typical Rural Setting in the Equatorial Rainforest of the South West Region of Cameroon. PLoS One. 2021 May 18;16(5):e0251380. PubMed PMID: 34003847.

79. Inah SA, Uwadeigwu Z, Eko JE, Inah JA. Environmental Sanitation Practices on Malaria Control and Prevention in Abi Local Government Area, Cross River State, Nigeria. Asian J Med Health. 2017;6(2):1-12.

80. Velayudhan R. Updated: VEM/NTD \& STAG 2019 [Internet]. Geneva: World Health Organization; 2019 [cited 2021 Aug 13]. Available from: https://www.who.int/docs/default-source/ malaria/vcag-documentation/vcag-may2019-stag-update. pdf?sfvrsn=dfef24ca 2 .

81. Mishra SR, Dhimal M, Bhandari PM, Adhikari B. Sanitation for All: the Global Opportunity to Increase Transgenerational Health Gains and Better Understand the Link between NCDs and NTDs, a Scoping Review. Trop Dis Travel Med Vaccines. 2017 Apr 26;3:8.

82. The Hindu. Stagnant Water Breeds Malaria, Dengue [Internet]. Chennai: THG Publishing PVT LTD.; c2021 [updated 2019 Jun 10; cited 2021 Aug 13]. Available from: https://www.thehindu.com/ news/national/telangana/stagnant-water-breeds-malaria-dengue/ article27706815.ece.

83. Yang D, He Y,Wu B, Deng Y, Li M, Yang Q, et al. Drinking Water and Sanitation Conditions are Associated with the Risk of Malaria among Children Under Five Years Old in Sub-Saharan Africa: A Logistic Regression Model Analysis of National Survey Data. J Adv Res. 2019 Sep 6;21:1-13.

84. Kashiwase H. Open Defecation Nearly Halved since 2000 but is still Practiced by 670 Million [Internet]. Washington (DC): The World Bank Group; c2021 [updated 2019 Nov 19; cited 2021 Aug 13]. Available from: https://blogs.worldbank.org/opendata/opendefecation-nearly-halved-2000-still-practiced-670-million.

85. Centers for Diseases Control and Prevention. Disease and SWS Impact [Internet]. Atlanta: U.S. Department of Health \& Human Services; c2021 [updated 2021 May 19; cited 2021 Aug 13]. Available from: https://www.cdc.gov/safewater/disease.html\#three. 